Nevşehir Bilim ve Teknoloji Dergisi Cilt 6(2) 563-570 2017

DOI: 10.17100/nevbiltek.354814

URL: http://dx.doi.org/10.17100/nevbiltek.354814

\title{
Farklı Oranlarda AI İçeren TRIP Çeliğinin Mig-Mag Kaynak Tekniği İle Kaynağı ve Mikroyapısının İncelenmesi
}

\author{
Cemal ÇARBOĞA*, Bülent KURT, Serkan DAL \\ Nevşehir Hacı Bektaş Veli Üniversitesi,Mühendislik Mimarlık Fakütesi,Metalurji ve Malzeme
}

Mühendisliği Bölümü, Nevşehir

$\ddot{O} z$

Günümüzde otomotiv sektörü için büyük öneme sahip olan dayanım, hafiflik, ekonomiklik ve şekillendirilebilirlik istenen önemli özelliklerdendir. TRIP (Transformation Induced Plasticity) çelikleri deforme olabilen yüksek mukavemetli ideal fazları ile otomotiv sektörü için son derece uygun bir yapı oluştururlar. Bu çalışmada, tipik TRIP çeliğinin mevcut alüminyum miktarı değiştirilerek vakumsuz indüksiyon ocağında farklı Al içeriğine sahip TRIP çeliği üretimi gerçekleştirilmiştir. Üretimi gerçekleştirilen TRIP çeliğinin $\mathrm{Al}$ oranı $0,4-0,8$ ve 1,4 oranlarında değiştirilmiştir. Daha sonra, elde edilen numunelerin birleştirilmesinde MIG-MAG kaynak tekniği kullanılmıştır. Elde edilmiş kaynaklı TRIP çeliklerinin, kaynak bölgesinin mikroyapı ve mikrosertlik profilleri çıarılmış ve elde edilen sonuçlar literatür ile karşılaştırılarak $\mathrm{Al}$ içeriğinin etkisi yorumlanmıştır.

Anahtar Kelimeler: TRIP Çeliği, Kaynak, Mikroyapı

\section{The Welding of TRIP Steel With Different Al Contents by Mig-Mag Welding Technique and Its Microstructure Investigation}

Abstract

Strength, lightness, economy and formability are important characteristics for the automotive sector, which has a high economic area today. TRIP (Transformation Induced Plasticity) creates a highly suitable structure for the automobile industry with high strength ideal phases which can be deformed. In this study, TRIP steel production with different Al content carried out by adding Al in TRIP steel with using non-vacuum induction furnace. Al content of the steel was changed to $0,4-0,8$ and 1,4 ratios. Then, the obtained samples were combined with the MIG-MAG welding technique. Microstructure and microhardness profiles of the welded TRIP steels were obtained and the results were compared with the literature and $\mathrm{Al}$ content was interpreted.

Keywords: TRIP Steel, Welding, Microstructure

\footnotetext{
*e-mail: ccarboga@nevsehir.edu.tr
} 


\section{Giriş}

Günümüzde otomotiv sektörü için yüksek öneme sahip olan yakıt tasarrufu, dayanım, hafiflik, ekonomiklik ve şekillendirilebilirlik önemli istenen özelliklerdendir. HSLA (yüksek mukavemetli düşük alaşımlı) çelikleri deforme olabilen yüksek mukavemetli ideal fazları ile otomobil sektörü için son derece uygun bir yapı oluştururlar[1,10-13]. Bu özellikleri yanında HSLA çelikleri, otomobil parçaları için hafif olması ve darbe sönümleme özelliği ile yolcu güvenliği açısından son derece önemli malzemelerdir[1-9, $11]$.

HSLA çelikleri genellikle $300 \mathrm{MPa} ı n$ üzerinde bir akma dayanımı ve $600 \mathrm{MPa}$ 'dan daha yüksek gerilme mukavemeti gösterirler. Ayrıca HSLA çeliklerinden söz edilirken, çift fazlı (DP), dönüşümden kaynaklı plastisite (TRIP), kompleks faz (CP) ve martensitik (M) çeliklerden bahsedilir. HSLA çeliklerinden TRIP çelikleri ferrit, beynit, martensit ve karbonca aşırı doymuş östenit gibi çeşitli yapısal bileşenleri sayesinde sert yumuşak kompozit yapıya bağlı olarak iyi bir üniform uzama ile birlikte yüksek mukavemete sahiptirler. TRIP çeliklerinin tipik bir mikroyapısı yaklaşık \% 40-60 ferrit, $\% 25$ beynit ve\% 10-15 kalıntı östenit içermektedir[14]. TRIP çelikleri sementit oluşumunu bastırmak için genellikle alaşımlıdır.Si ve Al sementit içerisinde çözünmediğinden östenit içerisinde daha fazla karbon çözünmeye zorlamaktadırlar[11]. Si'nin yüksek oranlarda kullanımı çeliğin galvanizleme, sıcak haddeleme ve kaynak özelliklerinde sorunlara sebep olup yerine kullanılabilecek elementler ile ilgili çalışmalar yapılmaktadır[14]. Al ve Si periyodik tabloda birbirine yakın konumda bulunmakta ve fiziksel ve kimyasal özelliklerin yanı sıra benzer atomik yapı sergilemektedir. Al'nin, TRIP çeliğindeki Si yerine kullanılabilirliği çalışmalarda belirtilmiştir[12]. Si’nin yerini Al aldığında TRIP çeliklerinin mekanik özelliklerinde hiçbir fark görülmediği; ancak çekme testi sırasında ilginç bir şekilde C-Mn-Al TRIP çeliğinin C-Mn-Si TRIP çeliğine kıyasla dikkate değer bir TRIP etkisi sergilediği görülmüştür[11].

Bu çalışmada, farklı Al içerikli TRIP çelikleri robotik MIG-MAG kaynak yöntemiyle $08 \emptyset(\mathrm{mm})$ alaşımsız çelik tel kullanılarak tek pasoda birleştirilmiştir. Birleştirme sonrası kaynak bölgesi mikro yapısı ayrıntılı olarak incelenmiş ve kaynak bölgesi kesitinden bir dizi mikrosertlik alınarak ana malzeme, ITAB ve kaynak metalini kapsayan kaynak kesiti mikrosertlik profili çıkarılmıştır.

\section{Materyal ve Metot}

Bu çalışmada, 5 mm'lik kalınlığa sahip farklı oranlarda Al içerikli TRIP çelikleri robotik MIG MAG kaynak tekniği ile tek pasoda birleştirilmiştir. Kullanılan numunelerin kimyasal bileşimleri Tablo 1'de görülmektedir.

Tablo 1. Deneyde kullanılan farklı oranlarda $\mathrm{Al}$ içeren TRIP çeliği numunelerin kimyasal bileşimleri.

\begin{tabular}{ccccccccc}
\hline $\begin{array}{c}\text { Numune } \\
\text { No }\end{array}$ & $\mathbf{C}$ & $\mathbf{M n}$ & $\mathbf{S i}$ & $\mathbf{B}(\mathbf{p p m})$ & $\mathbf{A l}$ & $\mathbf{T i}$ & $\mathbf{P}$ ve $\mathbf{S}$ & $\mathbf{F e}$ \\
1 & 0,13 & 1,83 & 0,29 & 0,0008 & $\mathbf{0 , 3 3}$ & 0,0055 & $0,018-0,012$ & 97,11 \\
2 & 0,10 & 1,87 & 0,32 & 0,0007 & $\mathbf{0 , 8 3}$ & 0,0065 & $0,018-0,012$ & 96,64 \\
3 & 0,11 & 1,90 & 0,33 & 0,0009 & $\mathbf{1 , 4 2}$ & 0,0082 & $0,018-0,014$ & 96,96 \\
\hline
\end{tabular}

Döküm işlemi sonrası haddeleme ile $5 \mathrm{~mm}$ kalınlığında lama haline getirilen malzemeler 115x65x4 mm'lik boyutlarda kesilerek hazırlanmış ve Tablo 2'deki şartlarda tek pasoda kaynak edilmiştir. 
Tablo 2. Farklı oranlarda Al içeren TRIP çeliği için kaynak șartları.

\begin{tabular}{cccccc}
\hline $\begin{array}{c}\text { Akım şiddeti } \\
(\mathbf{A})\end{array}$ & Kullanılan Gaz & Marka-Yöntem & $\begin{array}{c}\text { Tel Çıkma Hızı } \\
\text { mm/saniye }\end{array}$ & $\begin{array}{c}\text { Paso Sayısı } \\
\text { Kullanılan Dolgu } \\
\text { Teli }\end{array}$ & $\begin{array}{c}\text { Alaşımsız çelik tel } \\
(0.8 \emptyset \mathrm{mm})\end{array}$ \\
\hline
\end{tabular}

Kaynak işlemi gerçekleştirildikten sonra numuneler oda sıcaklı̆ı̆ında kendi halinde açık havada soğutulmuştur. MIG MAG kaynak tekniği ile birleştirilen numunelerden, birleşme bölgesinin metalografik olarak incelenmesi amacıyla, kaynak bölgesi ve ısıdan etkilenen bölgeyi kapsayacak şekilde hassas kesme makinesiyle metalografik muayene numunesi çıarıldı. İncelenecek yüzeyler $1 \mu \mathrm{m}$ 'luk elmas pastayla parlatıldı. Parlatılan yüzeyler mikroyapısal muayene için, \% 3'lük Nital çözeltisinde 6 sn süre ile daldırma yöntemi kullanılarak dağlama işlemine tabi tutuldu. Dağlanan numunelerin mikroyapı incelemeleri optik mikroskop kullanılarak gerçekleştirildi. Kaynak metali ve ana malzeme arasındaki sertlik farklarını ortaya koymak amacıyla kaynak metali, ITAB ve ana malzemeyi de kapsayacak şekilde mikrosertlik ölçümleri gerçekleştirildi.

\section{Bulgular}

Birleştirilen numunelere ait kaynak dikişi ve kaynak kesitini gösteren fotoğraflar Şekil 1'de görülmektedir. Fotoğraflardan, kaynak dikişlerinde tam nüfuziyet sağlandığı ve kaynak dikişi görünümünde ise son derece düzenli ve homojen bir kaynak formunun meydana geldiği görülmektedir. Kaynak metali kesitinden ve aynı zamanda optik mikroyapı incelemelerinden yaklaşık 5 mm'lik bir ITAB bölgesinin meydana geldiği görülmüştür.

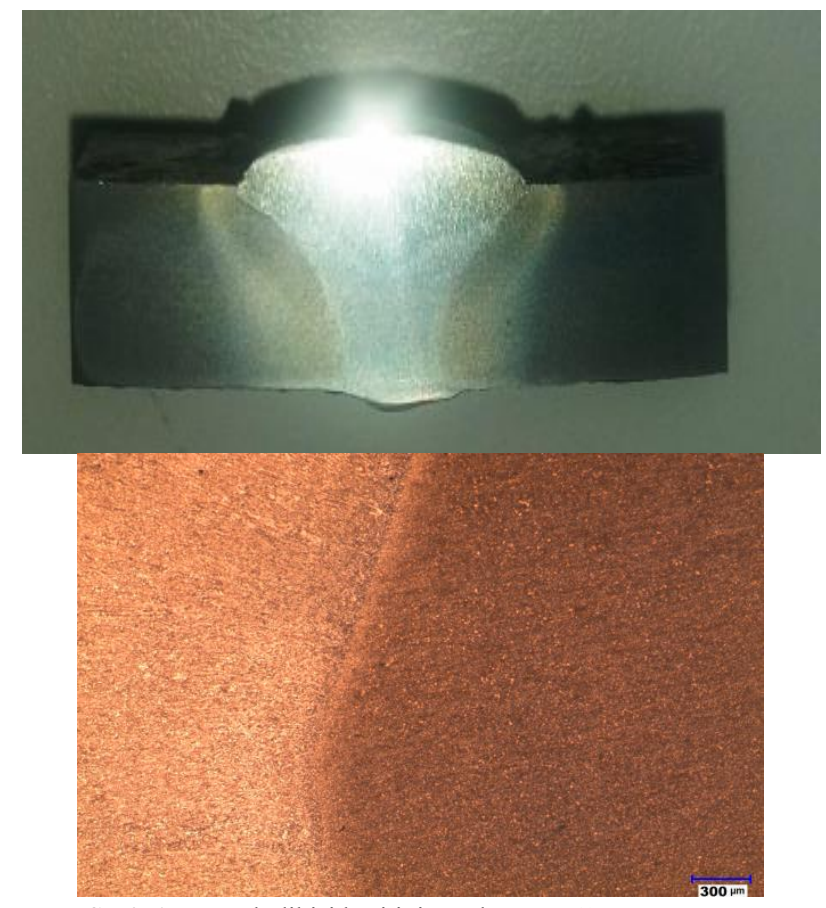

Şekil 1. Kaynak dikişi kesitinin makro ve mikro görünümü.

Şekil 2'de sırasıyla TRIP çeliğine Al oranı \% 0,4 - 0,8 - 1,4 oranlarında ilave edilmiş numunenin kaynak metali mikroyapıları görülmektedir. Kaynak metali mikroyapısının genellikle ferrit + çıta beynitik yapı oluşumu şeklinde meydana geldiği görülmektedir. Bununla birlikte \% 0,4 Al içerikli numunede 
kalıntı ostenit fazının da mikroyapıda bulunduğu tespit edilmiştir. Kučerová ve Bystrianský tipik bir TRIP çeliğinin ferrit+beynit+kalıntı ostenit mikroyapısına sahip olduğunu belirtmişlerdir[14]. Artan Al içeriği ile birlikte tane yapısının küçüldüğü beynitik yapı içerisindeki sementit çıtalarının daha da belirginleştiği açıkça görülmektedir(Şekil.2.c)

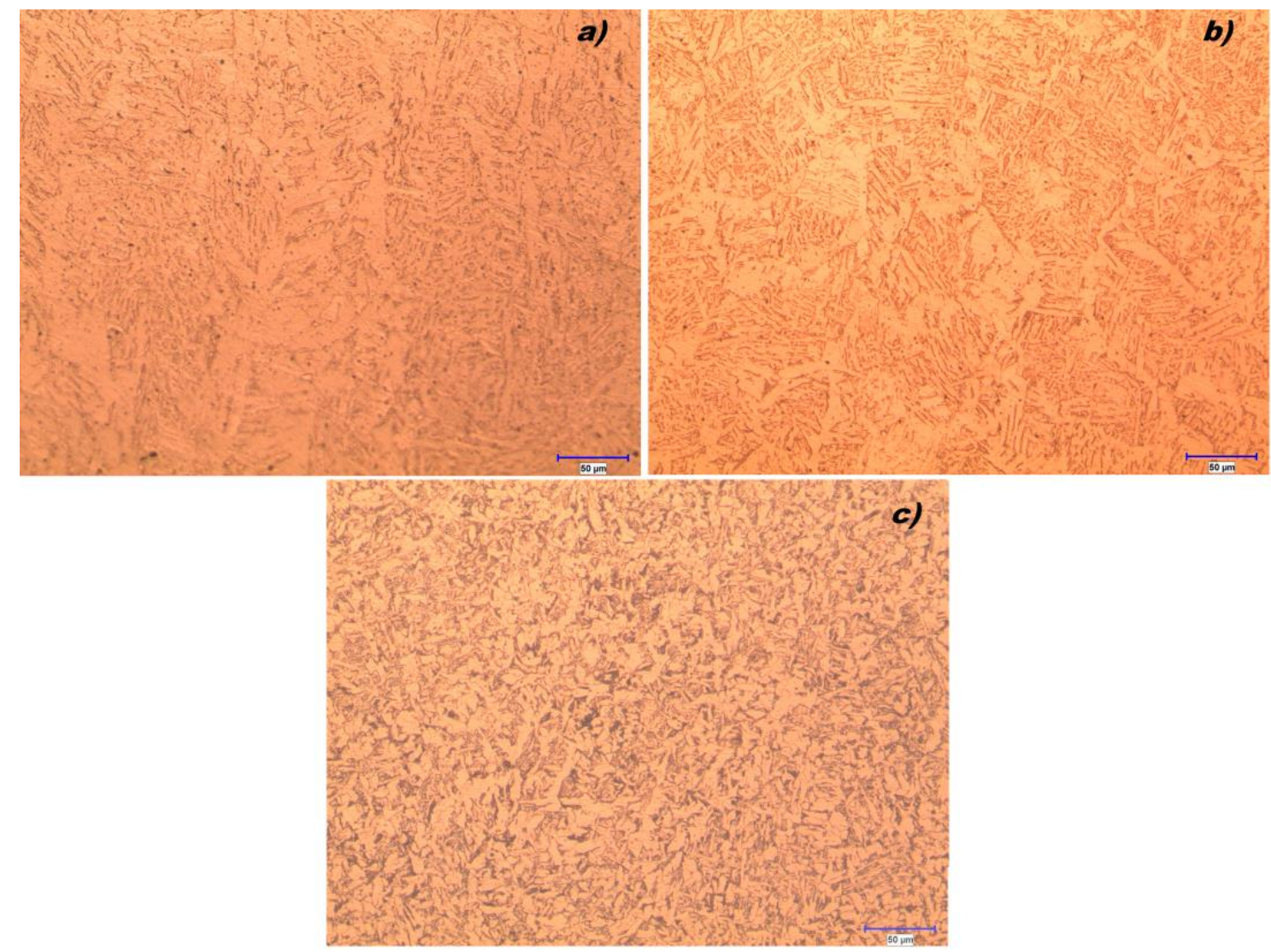

Şekil 2. Kaynak Metali Optik Mikroyapı Fotoğrafları a) \%0,4 Al, b) \%0,8 Al, c) \%1,4 Al.

Farklı oranlarda Al içeren numunelerin kaynak metali ve ITAB ara bölgeden alınan optik mikroyapı fotoğrafları Şekil 3 ’te görülmektedir. \%0,4 Al ve \%0,8 Al içeren numunelerde yapı genellikle beynit iken \%1,4 Al içeren numunede ferrit+perlit yapı oluşumu meydana gelmiştir. Kaynak metali ve ITAB ara bölgesinden alınan optik mikroyapı fotoğraflarından özellikle ITAB bölgesinde 0,4 ve 0,8 Al içeriklerinde beynit+ ferritik mikroyapı oluşumunun meydana geldiği görülürken 1,4 Al içekli numunede perlit+ ferritik mikroyapının meydana geldiği ve ince taneli yapı oluşumunun meydana geldiği açıkça görülmektedir.

MIG-MAG kaynak tekniği kullanılarak birleştirilen numunelerin ITAB bölgesinden alınan optik mikroyapı fotoğraflarından (Şekil 4) oluşan yapının martenzit ve beynit ağırlıklı olduğu gözlemlenmekle birlikte artan mikroalaşım Al oranına bağlı olarak \%0,4 Al içerikli numunede ferrit+ beynit, \%0,8 Al içerikli numunede yönlenmiş ferrit+beynit, \%1,4 Al içerikli numunede ise ferrit+perlit+beynitik mikroyapının meydana geldiği görülmektedir. 
Nevşehir Bilim ve Teknoloji Dergisi Cilt 6(2) 563-570 2017
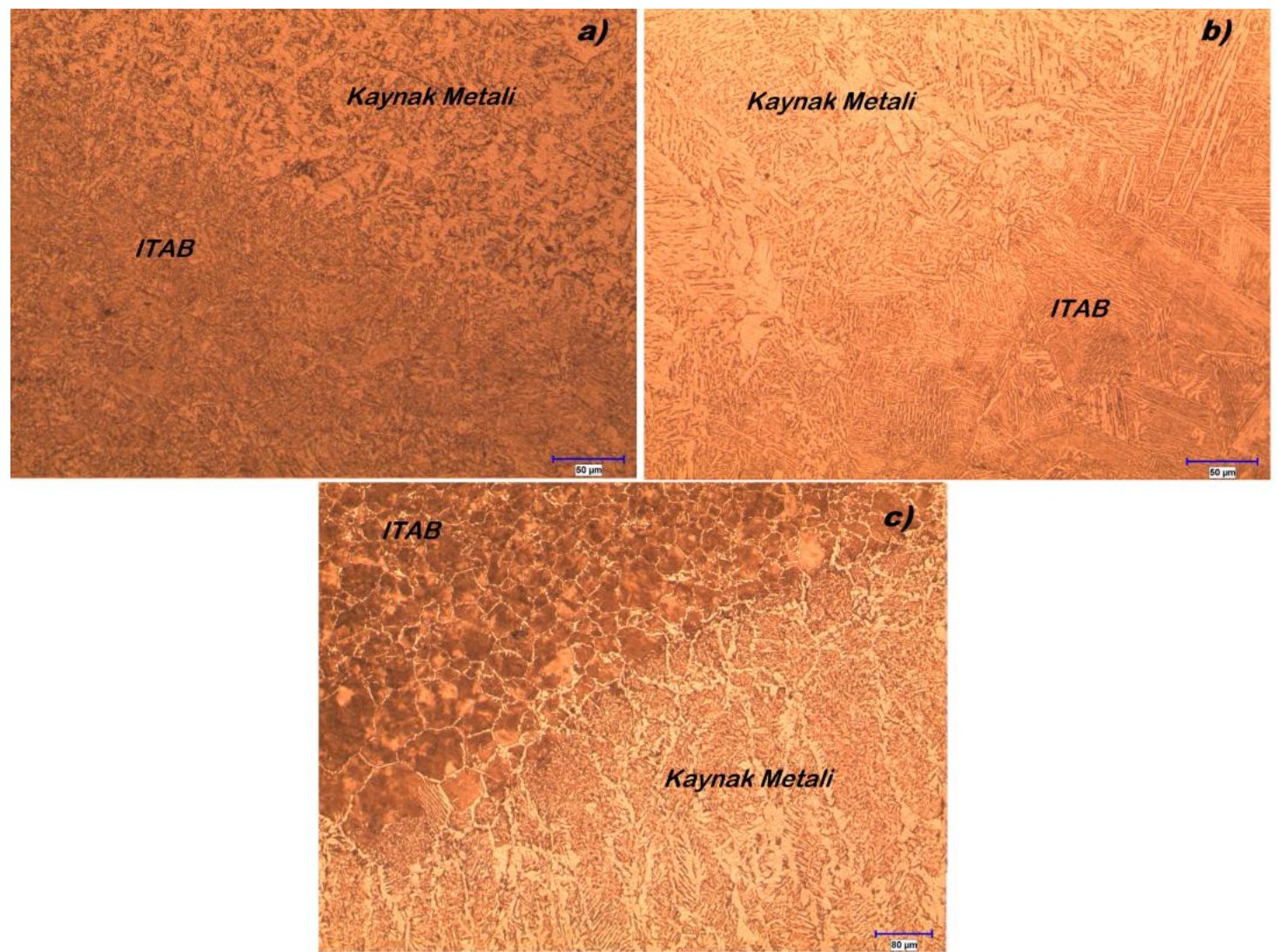

Şekil 3. Kaynak Metali-ITAB Ara Bölgesinin Optik Mikroyapı Fotoğrafları [a)\%0,4 Al, b) \%0,8 Al, c) \%1,4 Al]
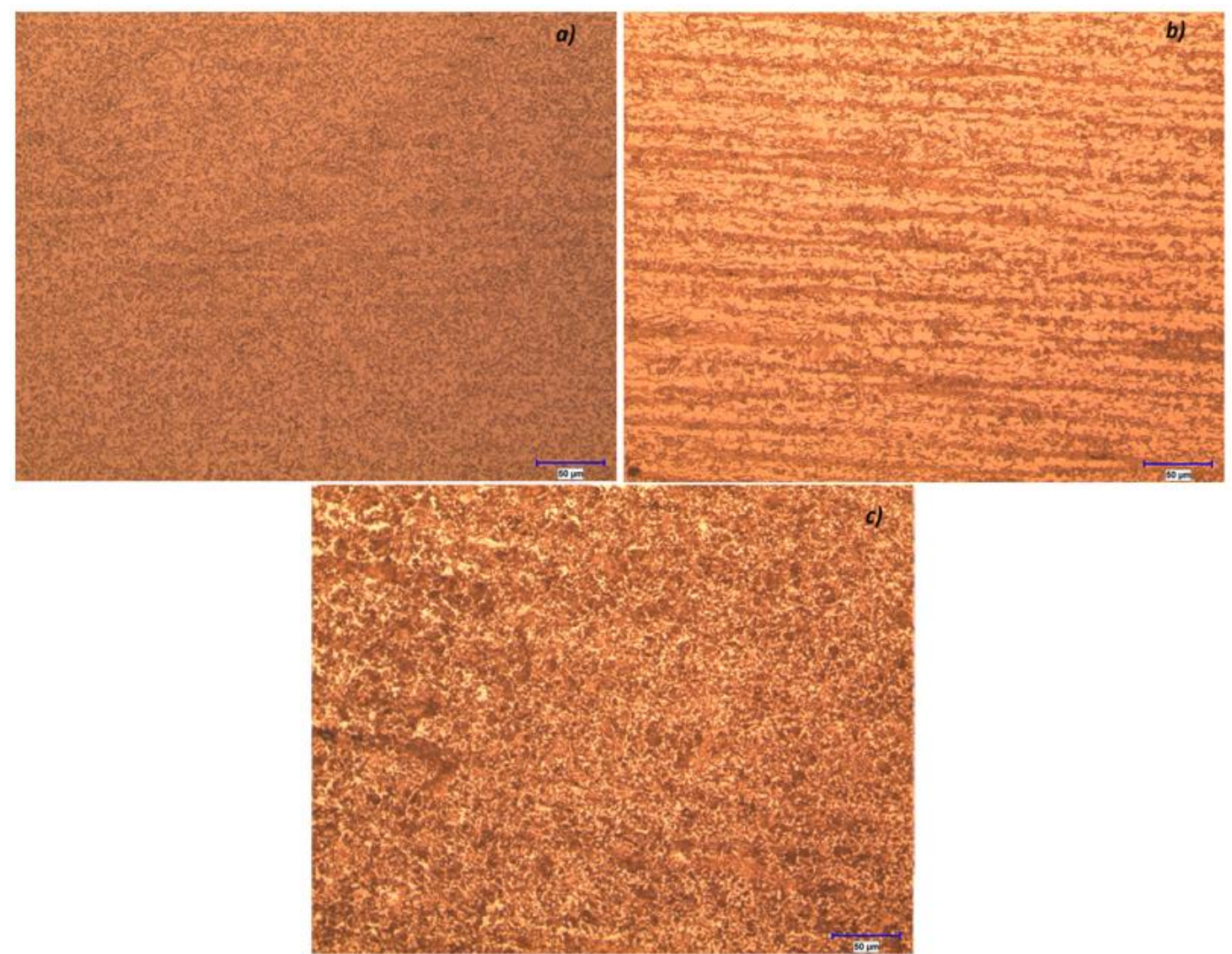

Şekil 4. ITAB Bölgesinin Optik Mikroyapı Fotoğrafları [a)\%0,4 Al, b) \%0,8 Al, c) \%1,4 Al] 
Şekil 5’te \%1,4 Al içeriğine sahip TRIP çeliğinin kaynak metali ile ITAB bölgesinden alınan sertlik izi fotorafı görülmektedir. Mikrosertlik izi fotoğrafından kaynak metalinde ITAB bölgesinden alınan sertlik izlerine nazaran daha büyük bir izin oluştuğu görülmektedir. Farklı oranlarda Al içerikli TRIP çelikleri numunelerin bir çizgi halinde kaynak metali, ITAB ve ana malzemeden alınan mikrosertlik profilleri Şekil 6'da görülmektedir. Yine mikrosertlik profillerinden kaynak metali mikrosertliğinin ITAB bölgesine nazaran daha düşük çıktığı ve artan Al oranlarıyla mikrosertlik değerlerinde kayda değer bir değişime sebep olmadığı görülmektedir. Özellikle 0,4 ve 0,8 Al içeriğinde kaynak metali-ITAB ara bölgede 1,4 Al içerikli numuneye kıyasla daha yüksek bir sertlik değerinin ölçüldüğü görülmektedir.

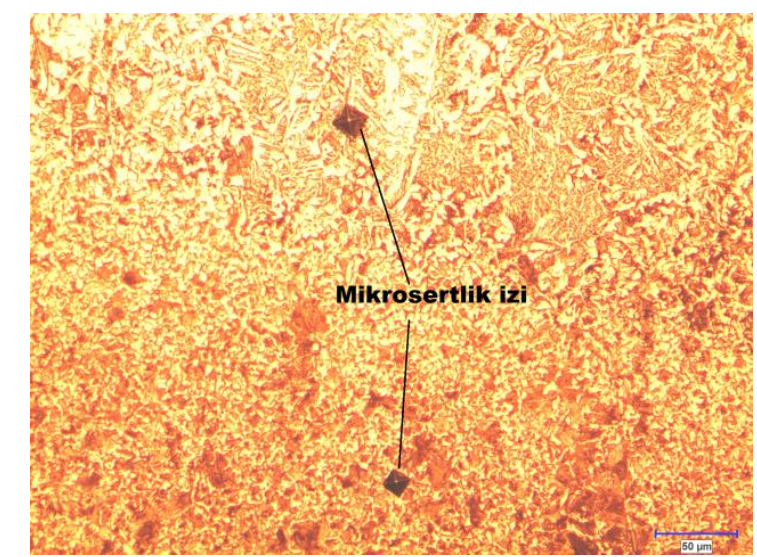

Şekil 5. \%1,4 Al içeriğine sahip TRIP çeliğinin kaynak metali ve ITAB Bölgesi Sertlik İzi Optik Fotoğrafi.

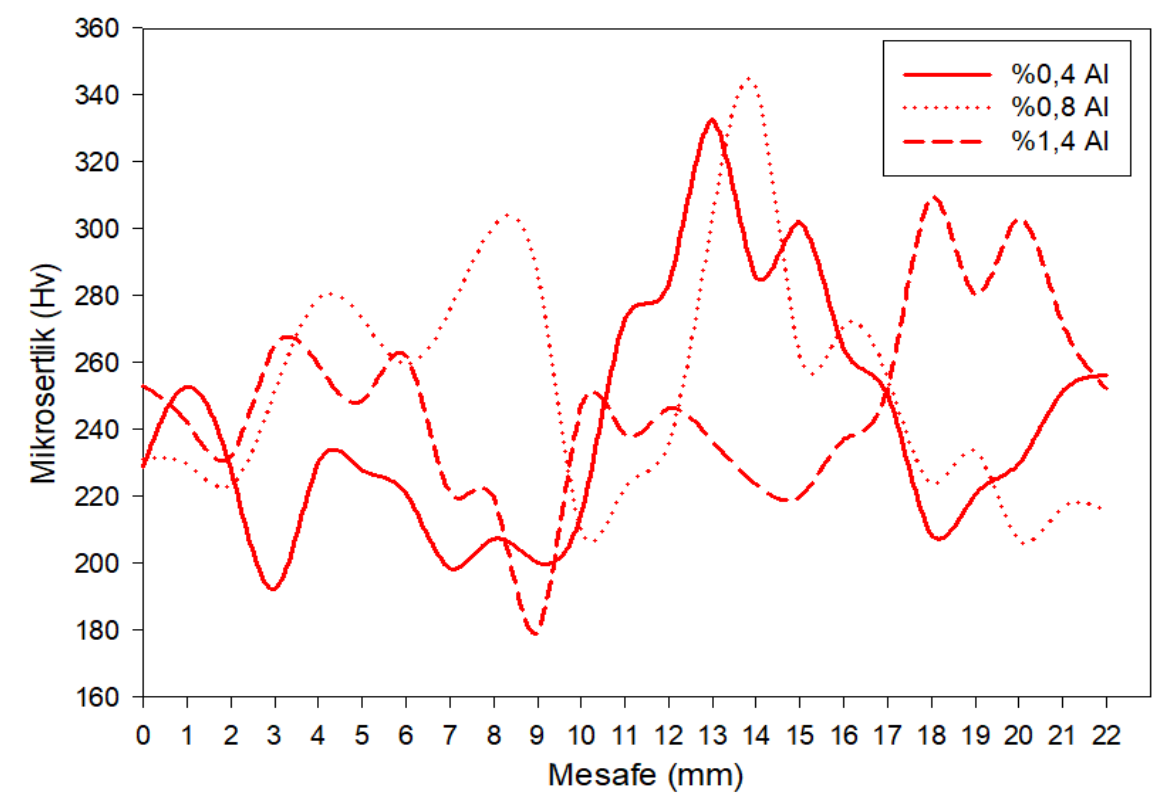

Şekil 6. Kaynak Metali, ITAB ve Ana Malzeme Mikrosertlik Profili.

\section{Tartışma ve Sonuç}

Farklı oranlarda Al içerikli TRIP çelikleri robotik MIG-MAG kaynak tekniği kullanılarak birleştirilmiş ve Al oranının TRIP çeliğinin kaynak edilebilirliği üzerindeki etkileri araştırılmıştır. Kaynak metali ve ITAB üzerine yoğunlaşılan çalışmada şu sonuçlara ulaşılmıştır.

- Tüm numunelerde çok iyi nüfuziyetli ve mikro çatlak oluşumunun gözlenmediği kaynak dikişileri elde edilmiştir. 
- Artan Al oranına bağlı olarak ferrit+beynitik yapı oluşumuyla birlikte perlitik yapının da meydana geldiği görülmüştür.

- 1,4 Al içerikli numunenin ITAB-kaynak metali ara bölgesinde tane boyutunun küçüldüğü ve ferrit+perlitik yapının meydana geldiği görülmüştür.

- $\mathrm{Al}$ artışının kaynak bölgesi mikrosertlik profili üzerine çok önemli bir etkisi olmamıştır.

\section{Kaynaklar}

[1] Liang J., Zhao Z., Zhang C., Tang D., Yang S., Liu W., Microstructure evolution and mechanical properties influenced by austenitizing temperature in aluminum alloyed TRIP aided steel, Journal of Iron and Steel Research, International, 24, 1115-1124, 2017.

[2] Arcelor Mittal , "How Will We Achieve: Safe Sustainable Steel?", Corporate Responsibility Report, 1-50,U.K. 2008.

[3] Demir B., “An Investigation Of Producability Of Dual-Phase Steel At The Continuous Annealing Line Of Eregli Iron And Steel Plant” PhD thesis, Gazi University, Ankara, 2003.

[4] Sakuma Y., Matlock D. K. and Krauss G., "Intercritically annealed and isothermally transformed 0.15 Pct C steels containing 1.2 Pct Si-1.5 Pct Mn and 4 Pct Ni: Part I. transformation, microstructure, and room-temperature mechanical properties", Metallurgical Transactions A, 23(4), 1221-1232, April, 1992.

[5] Jacques P. J., Girault E., Harlet PH. and Delannay F., “ The Developments of Cold-rolled TRIPassisted MultiphaseSteels.Low ilicon TRIP-assisted Multiphase Steels”, ISIJ International, 41(9), 1061-1067, 2001.

[6] Etienne girault 'Comparison Of The Effect Of Si And Al On The Tensile Behaviour Of Multiphase Trip-Assisted Steel', Scripta Metar. 44, 885-892, 2001.

[7] Jacques P. J., Grrault E.,. Harlet ph and Delannay F., "The Developments of Cold-rolled TRIPassisted Multiphase Steels. Low Silicon TRIP-assisted Multiphase Steels”, ISIJ International, 41(9), 1061-1067, 2001.

[8] Ildır B., Erden E., Çarboğa C. Ve Demir B., "TRIP Çeliği Üretilebilirliğinin İncelenmesi” $7^{\text {th }}$ International Advanced Technologies Symposium (IATS'13), 30 October-1 November,, Istanbul, Turkey, 2013.

[9] Hayat F, "TRIP Çeliklerinin Otomotiv Endüstrisindekullanımının İncelenmesi”, Gazi Üniv. Müh. Mim. Fak. Der. J. Fac. Eng. Arch. Gazi Univ., 25(4), 701-712, 2010.

[10] Lun N., Saha D.C., Macwan A., Pan H., Wang L., Goodwin F., Zhou Y., "Microstructure and mechanical properties of fibre laser welded medium manganese TRIP steel", Materials and Design 131, 450-459, (2017).

[11] Nayaka S.S., Baltazar Hernandeza V.H., Okitaa Y., Zhou Y., "Microstructure-hardness relationship in the fusion zone of TRIP steel welds", Materials Science and Engineering A, 551, 73-81, 2012.

[12] Li L., De Cooman B.C., Iju R., Vleugels J., Zhang M. , Shı W., "Design of TRIP Steel With High Welding and Galvanizing Performance in Light of Thermodynamics and Kinetics", Journal Of Iron And Steel Research, Internatıonal., 14(6), 37-41, 2007. 
[13] Wang C., Ding H., Cai M, Rolfe B., "Characterization of microstructures and tensile properties of TRIP-aided steels with different matrix microstructure”, Materials Science\&Engineering A, 610, 65-75, 2014.

[14] Kučerová L., Bystrianský M., Comparison of thermo-mechanical treatment of C-Mn-Si-Nb and C-Mn-Si-Al-Nb TRIP steels, Procedia Engineering 207, 1856-1861, 2017. 